\title{
High-Performance Liquid Chromatograph (HPLC) Equipped with a Neurophysiological Detector (NPD) as a Tool for Studying Olfactory System Intoxication by the Organophosphate (OP) Pesticide Diazinon and the Influence of $O P$ Pesticides on Reproduction
}

\author{
Ilia Brondz \\ Norwegian Drug Control and Drug Discovery Institute (NDCDDI) AS, Ski, Norway \\ Email: ilia.brondz@gmail.com \\ Received 25 February 2015; accepted 29 March 2015; published 30 March 2015 \\ Copyright (C) 2015 by author and Scientific Research Publishing Inc. \\ This work is licensed under the Creative Commons Attribution International License (CC BY). \\ http://creativecommons.org/licenses/by/4.0/ \\ (c) () Open Access
}

\begin{abstract}
A neurophysiological detector (NPD) is a hybridization of olfactory system neurons of the fish crucian carp, Carassius carassius L., with a computerized electronic device connected to a high-performance liquid chromatograph (HPLC). This system makes it possible to measure neurophysiological activities in the olfactory system of $C$. carassius $L$. after exposure of this fish to alarm pheromones. The construction of the system was presented for the first time at the $3^{\text {rd }}$ International Symposium on Separation in Bio Sciences SBS 2003 in I. Brondz, et al., The Fish Olfactory System Used as an In-Line HPLC Neurophysiologic Detector NPD, $3^{\text {rd }}$ Int. Symposium on Separation in Bio Sciences SBS 2003: A 100 Years of Chromatography, 13-18 May, Moscow, Russia, 2003, Abstract 027, p. 95. A complete paper was published in I. Brondz, et al., Neurophysiologic Detector (NPD)-A Selective and Sensitive Tool in High-Performance Liquid Chromatography, Chromatography B: Biomedical Sciences and Applications, Vol. 800, No. 1-2, 2004, pp. 41-47, and the hybridization of living cells with an electronic device has been discussed (I. Brondz, et al., International Scientific-Technical Conference Sensors Electronics and Microsystems Technology (SEMST-1), 1-5 June, (Odessa), Ukraine, 2004, Plenum Lecture, Abstract p. 17; I. Brondz, et al., The European Chemoreception Research Organization ECRO 2004 Congress, 12-15 September, (Dijon), France, 2004, Abstract P-3; and I. Brondz, et al., Biosensors as Electronic Compounds for Detector in the High-Performance Liquid

How to cite this paper: Brondz, I. (2015) High-Performance Liquid Chromatograph (HPLC) Equipped with a Neurophysiological Detector (NPD) as a Tool for Studying Olfactory System Intoxication by the Organophosphate (OP) Pesticide Diazinon and the Influence of OP Pesticides on Reproduction. International Journal of Analytical Mass Spectrometry and Chromatography, 3, 14-24. http://dx.doi.org/10.4236/ijamsc.2015.31002
\end{abstract}


Chromatography (HPLC), Electronic Components and Systems, Vol. 3, No. 103, 2006, pp. 25-27). In the present study, an HPLC equipped with an NPD was used to assess the influence of organophosphate (OP) pesticides on olfactory sensory nerves and the modification of nerve signals from the olfactory organ. The results show that exposure of the olfactory system to OP pesticides can lead to disruption of normal reflexes and to significant suppression of individual sexual activity and, as a result, to the suppression of a population.

\section{Keywords}

Neurophysiological Detector, Alarm Pheromones, Sex Pheromones, Suppression of a Population, Suppression of Individual Sexual Activity, Organophosphate (OP) Pesticides, Diazinon, Endocrine Disruptors

\section{Introduction}

This paper is primarily concerned with the use of neurons from the olfactory epithelium (OE) and olfactory bulb (OB) of the fish Carassius carassius L. as a physiologically specific and sensitive detection tool [1]-[5] in toxicology studies of organophosphate (OP) pesticides as possible endocrine and sexual activity disruptors. The use of neurons from the $\mathrm{OE}$ and the $\mathrm{OB}$ of the nasal cavity and the brain of the fish as a neurophysiological detector (NPD) makes it possible to record significant changes in nervous activity of the olfactory system after exposure of the fish's OE to the OP pesticide diazinon. A high-performance liquid chromatograph (HPLC) equipped with a diode array detector (DAD) and an NPD can provide both the retention time $\left(R_{t}\right)$ of physiologically active substances and their specific influence on neurons in the OE and OB.

The simultaneous recording of both the $R_{t}$ of physiologically active substances and their specific influence on neurons from the $\mathrm{OE}$ and $\mathrm{OB}$ makes it possible to study the nature of OPs as disruptors of sexual activity and species reproduction. Correlations between the signals from a DAD and NPD give undisputable evidence that behavioral changes of the fish $C$. carassius $\mathrm{L}$. reflect structural changes in the signals from the olfactory organ after exposure to OPs. In addition to the direct toxicity of OPs as endocrine disruptors on the endocrine system of mammals [6], it was possible to connect the intoxication by OPs to neurophysiological signal modification and reflex disruption. This shows that OPs are potential neurophysiological, endocrine and reflex disruptors of sexual activity.

\subsection{The Chemosensory System}

Joy V. Browne wrote, "The chemosensory system is one of the earliest emerging systems in fetal development..." [7] and that "Smell is detected through the epithelium of the nasopharynx and taste through the tongue. Anatomical structures and innervation are already present in the first and early second trimesters..." in the paper "Chemosensory Development in the Fetus and Newborn" [7]. In [7], the author refers to humans when she writes, "However, they not only have a profound effect on how environmental information is detected and processed but also make significant contributions to cognitive and emotional interpretation of daily experiences, ..." Browne describes human fetal development and human reactions, although these observations are applicable to all living creatures.

In fishes, the sensory organs responsible for smell detection and information processing have been studied for nearly a century [8]-[16]. Study on [8] provides a good description of the chemosensory system in fish. Frish in [15] [16] connected the specific behavior of fish to the presence of alarm substances detected by a fish's olfactory organs. The attempts to isolate a single alarm substance in pure form are presented in [1]-[5].

The information generated as electrochemical signals in cells of the $\mathrm{OE}$ are conducted via the olfactory nerves (ONs) to the OB, and via the olfactory tract to the olfactory lobes of the forebrain [8] [17].

\subsection{Single-Unit Recording of Pheromone-Induced Activity in the OB}

The recording of electrical nervous activity of a single neuron or a few neurons with identical electrical activity 
patterns was described by Døving in [18], Meredith [19], Hamdani and Døving [20], Lastein [21] and Lastein et al. in [22] as a "single unit recording". This electrical nervous activity of a single neuron or a few neurons is the basis for measurements of the nervous responses of the olfactory system to alarm substances reported in [1]-[5] and correlates with the behavioral pattern of $C$. carassius $L$. in response to substances in aquaria and the behavior of fishes [23]. The same techniques were adopted in the experiments described in the present paper. Some modifications were made to ensure reproducibility in the volume of injected pheromone because this amount varied significantly between instances of hand injection with a syringe, and this variability could influence the signal response from single units.

\subsection{Influence of Alarm Pheromones on Fish Behavior and the Correlation with Nervous Activity in the $\mathrm{OE}$ and $\mathrm{OB}$}

The behavioral effects of alarm pheromones from fish skin extract have been thoroughly studied and are described in [15] [16] [23]. In [1]-[5], nervous activity was related to two individual peaks on the HPLC chromatogram [1]. The paper was presented in the opening session lecture [1] by Dr. Brondz at the $3^{\text {rd }}$ Int. Symposium on Separation in Bio Sciences SBS 2003: A 100 Years of Chromatography, 13-18 May 2003 in Moscow, Russia (Figure 1). The chromatogram from fish skin extract and nervous activity in the OB were presented in [1] and are shown in Figure 2. Registration of two individual peaks with $R_{t}$ of 5.454 and 19.077 min (Figure 2(a)) coincided with the registration of nervous activity in the OB. The skin extract was reprocessed, and two individual peaks were detected (Figure 2(b)) with $R_{t}$ of 4.889 and 20.900. The substances under both peaks induced nervous activity in the OB, which was recorded as specific alarm signals. The UV spectrum from the substance under the peak with an $R_{t}$ of 20.900 is presented as a three-dimensional UV spectrum in Figure 2(c) and as a traditional UV spectrum in Figure 2(d).

The work-up reprocessing of fish skin extract shows that at least two individual substances were present under every peak with $R_{t}$ of 5.454 and 19.077. By reprocessing, it was possible to clean up the active alarm substances with $R_{t}$ of 4.889 and 20.900 from the ballast. Homogeneity analyses of UV spectra by scanning of these two peaks with $R_{t} 4.889$ and 20.900 were performed and confirmed 95\% homogeneity. Additional analyses of the fluorescence spectra were performed. The substances had distinct fluorescence. This finding supports the



Figure 1. The paper [1] was presented by Dr. Brondz in the opening session lecture at the $3^{\text {rd }}$ International Symposium on Separation in Bio Sciences SBS 2003: A 100 Years of Chromatography, 13-18 May 2003 in Moscow, Russia. 


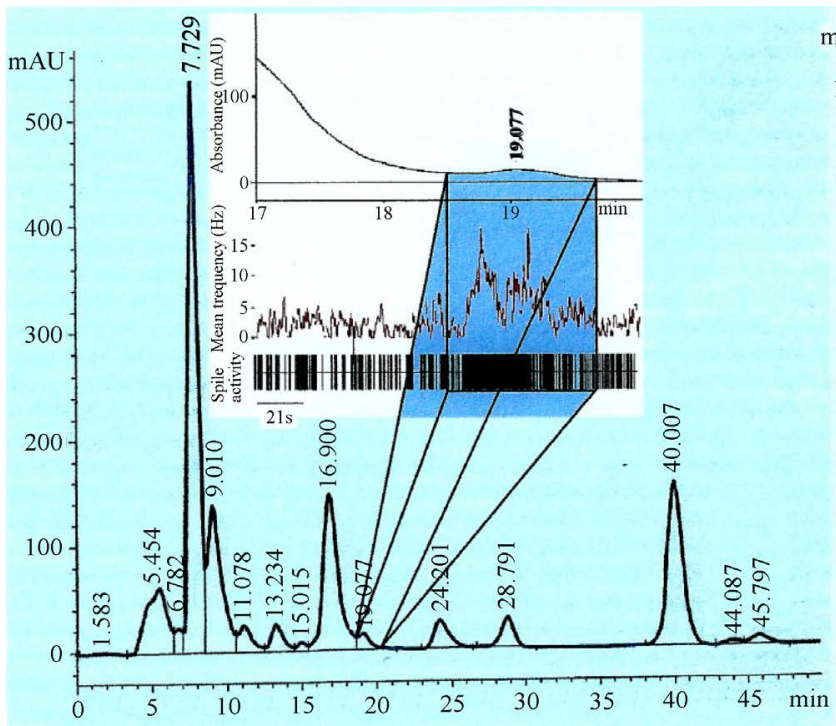

(a)

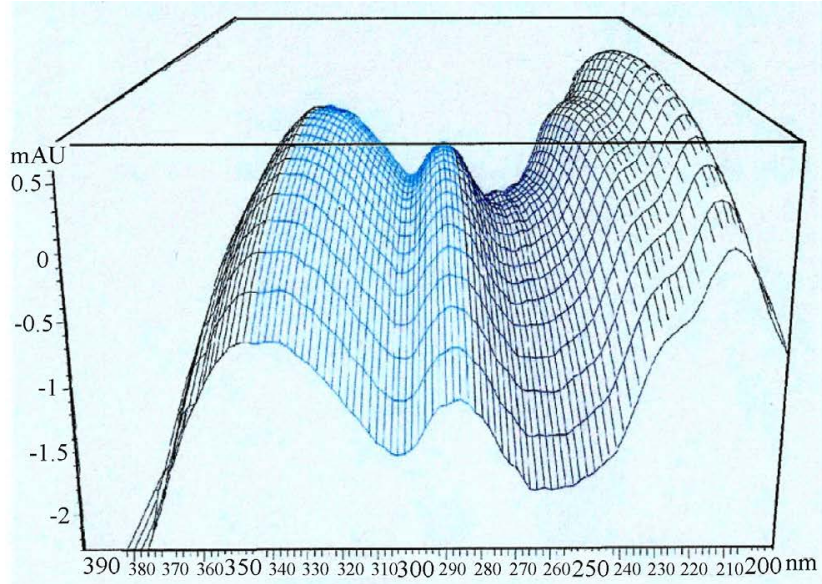

(c)

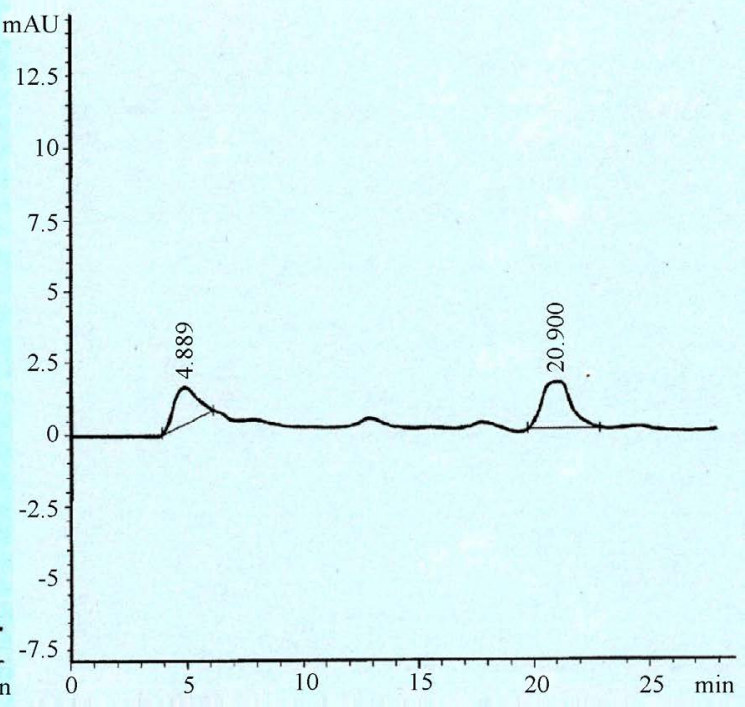

(b)

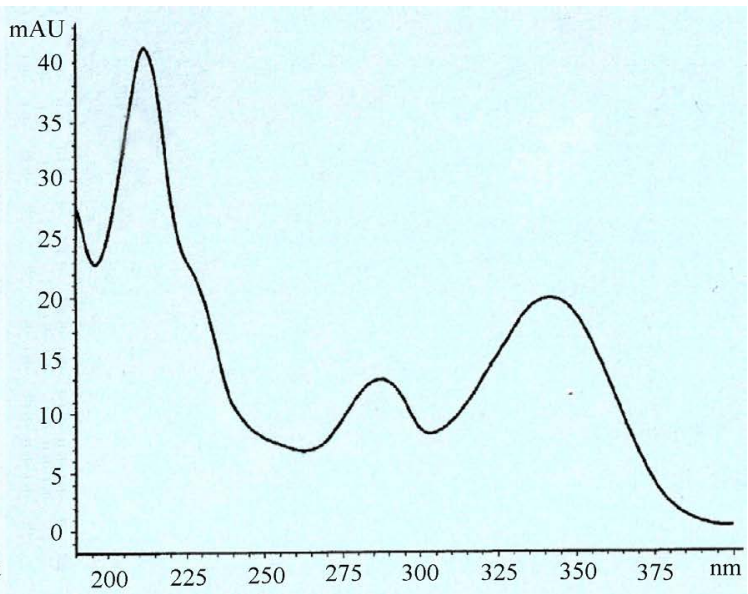

(d)

Figure 2. Chromatograms from fish skin extract and nervous activity in the OB. (a)-(d) are explained in the text above. Figure 2 is reproduced from the materials presented in the opening session lecture given by Dr. Brondz at the $3^{\text {rd }}$ International Symposium on Separation in BioSciences SBS 2003: A 100 Years of Chromatography, 13-18 May 2003 in Moscow, Russia.

hypothesis that the substances under these two peaks with $R_{t} 4.889$ and 20.900 were derivatives of pterins or folates; however, additional studies should be performed using mass spectrometry. The nature of alarm substances as pterins was proposed earlier by (Hüttel, 1941) [24], and it has also been proposed that the alarm substance of the European minnow is a purine or pterin-like substance ((Hüttel and Sprengling, 1943) [25], (Purrmann, 1947) [26], (Korte and Tschesche, 1951) [27], (Ziegler-Giinder, 1956) [28], (Pfeiffer and Lemke, 1973) [29] and (Lebedeva et al., 1975) [30]).

The HPLC fractions with $R_{t}$ from $19.9 \mathrm{~min}$ to 21.9 min were collected and combined. This liquid was introduced through thin polyethylene tubing into an aquarium with $C$. carassius L. The fish demonstrated behavior described previously in [16] and in other report [30]; this behavior was characteristic for C. carassius L. movements and included attempts to hide itself in the mud.

\subsection{The Influence of the Toxic Pesticide Diazinon and Other OPs on Fish Behavior}

The study by Scholz et al. [31] describes experiments involving exposure of fish to diazinon and the results on fish behavior. Two aspects of behavior were studied: antipredator and homing. The conclusions of this study 
were as follows. "The results of the antipredator experiment are consistent with the hypothesis that diazinon disrupts olfactory nervous system function..." and "Moreover, when compared with controls, diazinon-exposed chinook salmon parr showed a reduced antipredator response..." The homing reflex was also suppressed in this study, as noted by the following quotes: "In the homing study, fewer diazinon-treated fish returned to the... hatchery compared with control." and "The weight of evidence suggests that diazinon-exposed fish were less able to smell and thus were less able to navigate to their natal stream (Moore and Waring, 1996)” [31].

Other external observations of fish behavior after exposure to diazinon and other OP pesticides strongly support these conclusions and describe an array of other disorders in fish behavior after exposure to OP toxins. In water, under the influence of sun and oxygen from atmosphere, diazinon oxidizes to diazoxon, and the latter is more toxic in all ways than the former. Figure 3 shows the molecular structures of diazinon and diazoxon.

\subsubsection{What Are OPs? The History of the Discovery of the Toxic Activities of OPs}

Generally, OPs are phosphate esters of many important biologically active molecules such as DNA, RNA, and cofactors, and are constituents of insecticides, herbicides, and warfare nerve agents. The general molecular formula is given in Figure 4(a).

In agriculture and the military, the term OPs has a specific meaning as insecticides and warfare nerve agents, respectively, with anti-acetylcholinesterase enzyme activity. Pesticides and OPs such as sarin and VX (nerve agent) irreversibly inactivate acetylcholinesterase.

Philippe de Clermont and Wladimir P. Moshnin (1854) in Adolphe Wurtz's laboratory in Paris synthesized tetraethyl pyrophosphate (TEPP), the first cholinesterase inhibitor [32]. In 1932, Willy Lange and Gerde von Krueger first described the effects of OPs on the cholinergic nervous system. In the 1930s, Gerhard Schrader at IG Farben experimented with these compounds as insecticides. In the 1930s in Nazi Germany, the potential of OPs such as sarin (Figure 4(b)), tabun, and soman were considered to be more important as warfare nerve agents to kill humans than as insecticides in agriculture and veterinary practice. The production of sarin started in Nazi Germany.

Sarin, or GB, is an organophosphorus compound used as a chemical weapon and has been classified as a weapon of mass destruction in UN Resolution 687. A nonlethal dose of sarin causes neurological damage in both the peripheral and central nervous systems in insects and vertebrata (including fish and mammals).

\subsubsection{Mode of Bioneurological Toxicity of OPs}

OPs are anti-acetylcholinesterase agents that attack the peripheral and central nervous systems. Their action has been described as "The primary target for OP inhibition is acetylcholinesterase (AChE)" [33]. OPs are potent

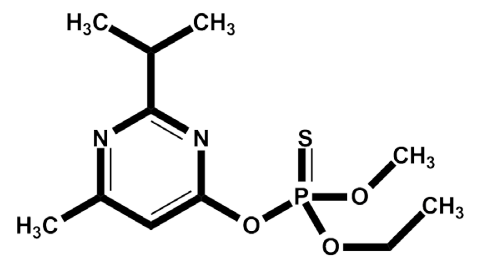

Diazinon

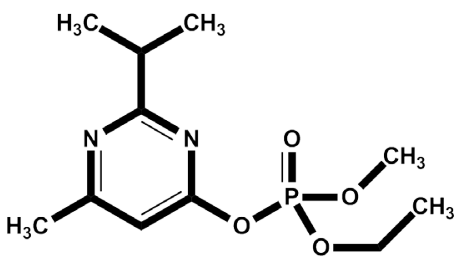

Diazoxon

Figure 3. The molecular structures of diazinon and diazoxon.<smiles>[R6]OP([R20])(=O)O[R6]</smiles>

Chemical structure of organophosphate

(a)<smiles>CC(C)OP(C)(=O)P</smiles>

(RS)-Propan-2-yl methylphosphonofluoridate

Sarin

(b)

Figure 4. Molecular structures of (a) OPs in general and (b) sarin. 
inhibitors of acetylcholinesterase, which degrades the neurotransmitter acetylcholine. Preventing acetylcholinesterase activity through exposure to OP leads to an accumulation of a high concentration of acetylcholine in the synaptic cleft or the synaptic junction. Nerve impulses are continually transmitted to muscles, excretory cells, and the brain. OPs can affect the brain through axoplasmic transport to ONs [34]. The important symptoms of exposure of secretory cells to OPs are a runny nose (actions of OPs on secretory cells in the olfactory organ), nausea, vomiting, involuntary defecation, and urination. In humans, exposure to OPs causes symptoms similar to those of the common cold and influenza even in warm environments and outside of influenza epidemics. The important symptoms of brain involvement in OP intoxication included impairment of the hypothalamic-hypophyseal-adrenal axis and endocrine and cognitive functions [33] [35]-[38]. Publications [33] and [35]-[38] present strong evidence of the axoplasmic transport of OPs in ONs [34] and through sensory nerves to the brain. The damage of telencephalic nerves by mechanical or chemical lesions can suppress behavioral patterns, as noted by Davis et al. [39].

\section{Materials and Methods}

\subsection{Preparation of the NPD}

\subsubsection{Biological Materials}

Crucian carp, C. carassius L. (20 - 35 g) were caught in a small lake in the vicinity of the rural city Ski, Norway (the lake is a nature reserve in summer). The fish were transported to the aquaria facilities at the Norwegian Drug Control and Drug Discovery Institute (NDCDDI) AS, Ski, Norway, for stabilization over one month and where they were fed three times a week. Fish were initially anesthetized with benzocaine ( $45 \mathrm{mg} / \mathrm{L})$ and immobilized by intraperitoneal injection of saffan (Schering-Plough Animal Health, Welvyn Garden City, UK) at 24 $\mathrm{mg} / \mathrm{kg}$ body weight. To prevent drying and to avoid any unforeseen movement during the experiment, the fishes were wrapped in a wet paper cloth and fixed by two steel rods, which were fastened to the upper parts of the orbital bones [1] [2]. Care was taken not to disrupt the tissue around the $\mathrm{OE}$ because damage to the skin causes release of alarm substances. Fish were irrigated continuously through the mouth and over the gills by artificial pond water (APW) during the experiment. Figure 5 shows a schematic drawing of the experimental set-up of the HPLC equipped with DAD and NPD, as described in [1]-[5] and modified in this experiment.

\subsubsection{Surgery and Conditioning}

The surgical procedure has been described in [2]. Conditioning of the olfactory organ was performed as described in [2] using APW NaCl (Merck, Darmstadt, Germany) $2.9 \times 10^{-2} \mathrm{~g} / \mathrm{L}, \mathrm{KCl}$ (Merck) $3.7 \times 10^{-3} \mathrm{~g} / \mathrm{L}$, $\mathrm{CaCl}_{2}$ (Merck) $5.8 \times 10^{-2} \mathrm{~g} / \mathrm{L}$, and $\mathrm{NaHCO}_{3}$ (Merck) $1.6 \times 10^{-2} \mathrm{~g} / \mathrm{L}$. A flow rate of $0.5 \mathrm{~mL} / \mathrm{min}$ in the system was regulated by the HPLC. The difference in delay between the DAD and microvalve 12 was $<0.2 \mathrm{~s}$, the delay between the DAD and OE in the nasal cavity of the fish was 2.9 - $3.0 \mathrm{~s}$ in different experiments (depending on the fish positioning). The total number of experiments was 19. The flow of the mobile phase was continuous in the experiments.

The active substances were introduced directly into the flow by microvalve 12 or by reconstructed Rheodyne injector 4, which allowed smooth switching of the flow between column 1 and column 2 and the injection of the biologically active substances. The change in flow of APW to APW with $10 \mathrm{ppm}$ of diazinon and reversion of flow from APW with $10 \mathrm{ppm}$ of diazinon to APW was performed by using Rheodyne injector 4 . The exposuretime of the OE to APW with $10 \mathrm{ppm}$ of diazinon in the nasal cavity of fish was $1.0 \mathrm{~min}$. Relaxation between experiments was performed using APW for 6.0 min.

The control measurements were performed using only APW before every experiment. Every experiment used only one fresh fish that had not been exposed to chemicals for the one-month stabilization in the aquaria facilities. A typical recording of single-unit activity (SUA) at a recording site in the OB using only mobile phase APW is shown in Figure 6(a). A typical recording of an SUA at a recording site in the OB after injection through microvalve 12 of $100 \mu \mathrm{L}$ of skin extracts is shown in Figure 6(c). A typical recording of an SUA at a recording site in the $\mathrm{OB}$ after injection of $100 \mu \mathrm{L}$ of a mixture of sex pheromones through Rheodyne injector 4 is shown in Figure 6(b). A typical recording of an SUA at a recording site in the OB after exposure of the fish OE to APW with $10 \mathrm{ppm}$ of diazinon and following injection of the $100 \mu \mathrm{L}$ of mixture of sex pheromones through Rheodyne injector 4 is shown in Figure 6(d). 


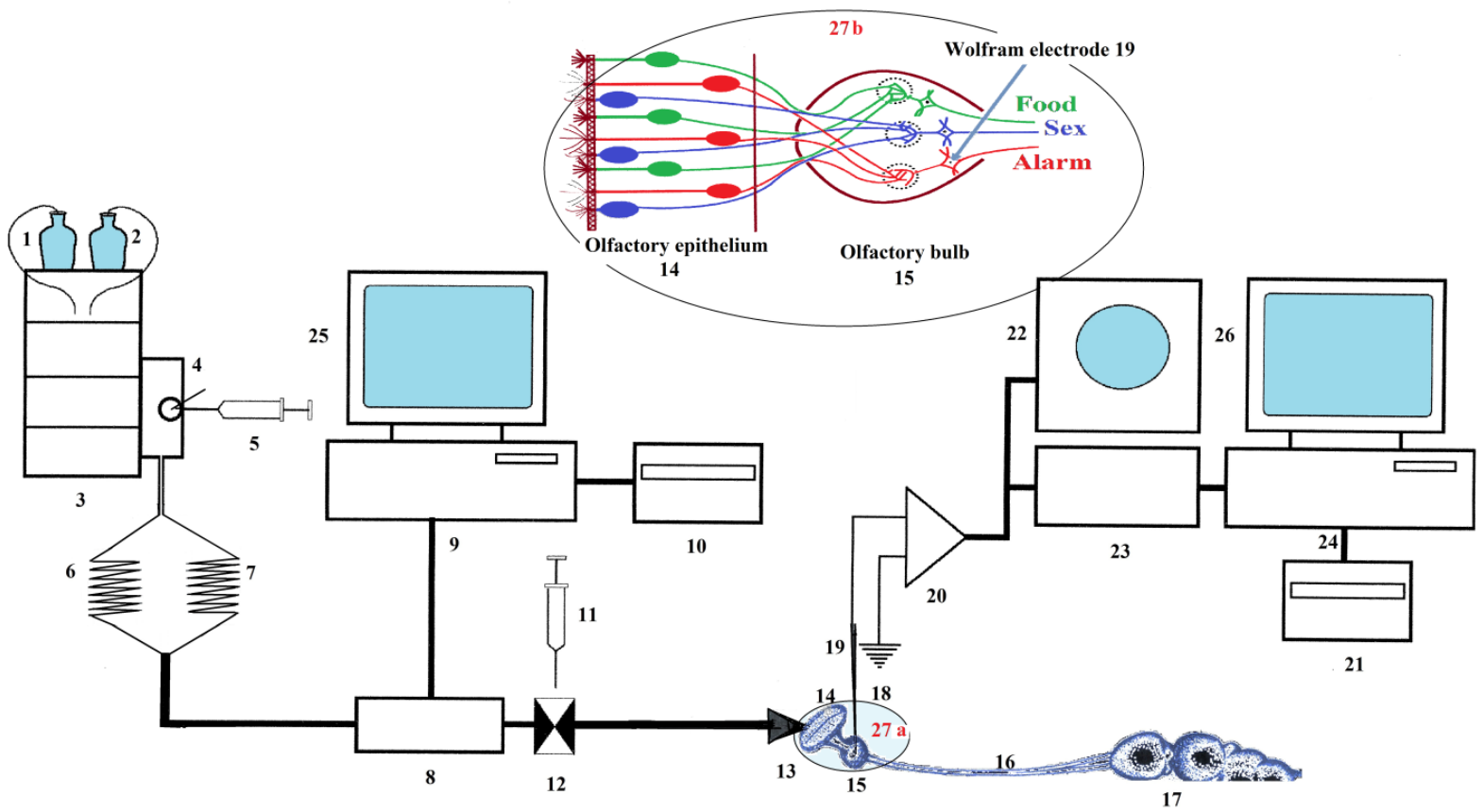

Figure 5. A schematic drawing of the experimental set-up of the HPLC equipped with DAD and NPD. The set-up included (1) reagent bottle 1 with APW; (2) reagent bottle 2 APW with 10 ppm of diazinon; (3) the HPLC system; (4) a Rheodyne injector; (5) a syringe with a mixture of sex hormones; (6) column 1; (7) column 2; (8) the DAD; (9) a data processor for the HPLC system; (10) data acquisition printer 1 for the HPLC system; (11) a syringe with fish skin extract; (12) a microvalve; (13) transference tubing; (14) OE; (15) OB; (16) olfactory tract; (17) telencephalon; (18) an earth ground connection; (19) a tungsten (wolfram) electrode; (20) an amplifier; (21) data acquisition printer 2 for the NPD; (22) an oscilloscope; (23) an AD converter; (24) a data processor for the NPD system; (25) a PC screen for the HPLC; (26) a PC screen for the NPD; (27a) the active detection part of the NPD; and (27b) the active detection part of the NPD in detail.

\subsubsection{Column Preparation}

Two HPLC Brownlee ${ }^{\mathrm{TM}}$ conventional columns $250 \mathrm{~mm}$ in length, $4.6 \mathrm{~mm}$ i.d. (PerkinElmer Instruments (Shelton, USA)) were used in the experiments. The support phase of the columns was removed, and all parts of the columns were cleaned with ethanol and distilled water. The columns were packed with river sand as the support phase using vibration, and sintered filters were installed on both sides of the columns.

\section{Preparation of the Support Phase (River Sand)}

River sand was obtained from a small lake in the vicinity of the rural city Ski, Norway (the lake is a nature reservation in summer). The sand was washed with distilled water, dried, defatted with $n$-hexane p.a. quality (Merck), washed with $1 \mathrm{M} \mathrm{NaOH}$ p.a. quality (Merck) for $1 \mathrm{~h}$, washed with $1 \mathrm{M} \mathrm{HCl}$ p.a. quality (Merck) for 1 $\mathrm{h}$, and finally washed with deionized water. The columns were installed in the HPLC and were flushed with APW for $1 \mathrm{~h}$ before the experiments.

\subsubsection{Experimental Protocol}

Each fish was prepared as described in paragraphs 2.1.1 and 2.1.2 and in publications [1]-[5]. The columns for HPLC were prepared as described in paragraphs 2.1.3 and 2.1.3.1, and the HPLC used was as described in paragraph 2.1 and in [2]. The chemicals used were: APW as described in paragraph 2.1.2, fish skin extract as described in [2], and a mixture of sex pheromones as described in [21]. The sample of diazinon was donated by Jupiter AS, Norway. The mobile phase in bottle 2 had a total concentration of $10 \mathrm{ppm}$ of fresh diazinon per $1 \mathrm{~L}$ of APW.

Two of the 19 experiments failed because of mistakes during surgery. Figures 6(a)-(d) show characteristic results. At the start of every experiment, the basal nervous activity at the measured site was measured by passing APW from bottle 1 through the nasal cavity for $10 \mathrm{~min}$. The experiment started when the nervous activity was stable. Experiments 1, 3, and 5 were as follows: $10 \mathrm{~min}$ at a flow rate of $0.5 \mathrm{~mL} / \mathrm{min}$ of APW from bottle 1 (characteristic results are shown in Figure 6(a)), after which $100 \mu \mathrm{L}$ of fish skin extract was injected through 


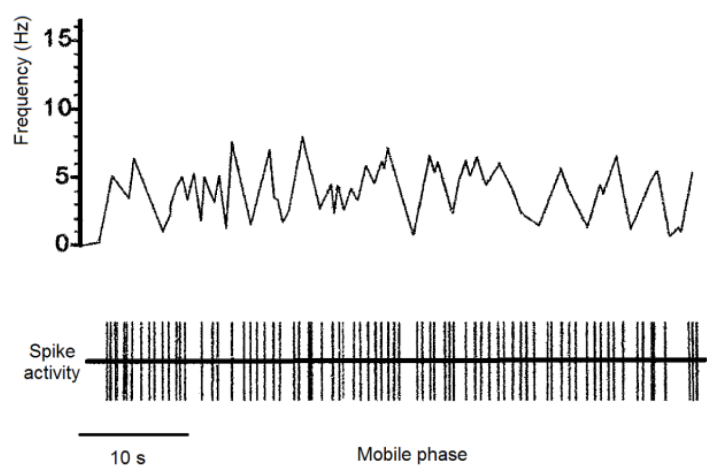

(a)

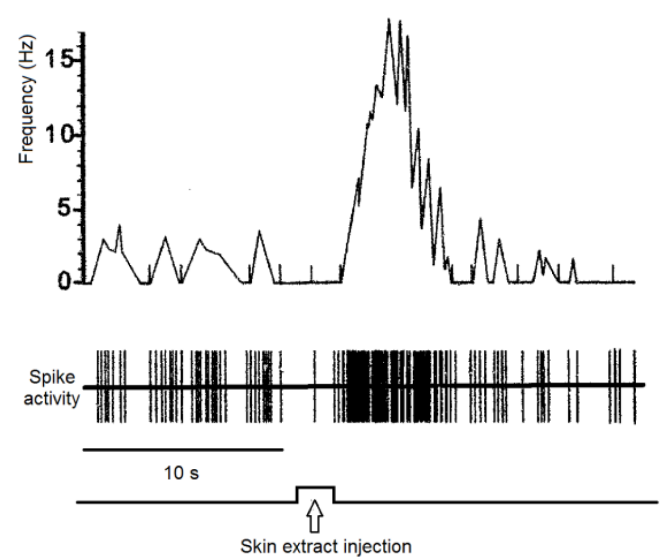

(c)

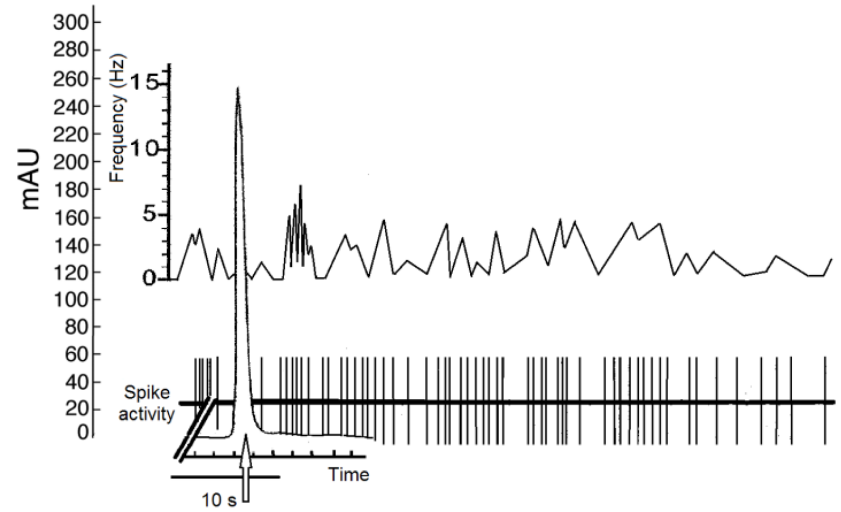

(b)

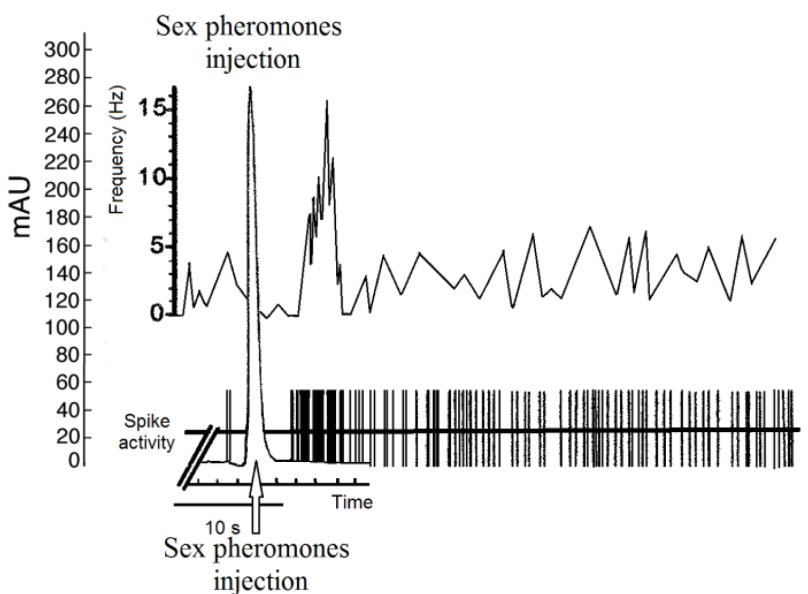

(d)

Figure 6. Nervous system activities recorded by the HPLC equipped with a DAD and an NPD. (a) A control; (b) After injection of a mixture of sex pheromones; (c) After injection of fish skin extract; (d) After injection of a mixture of sex pheromones and preexposure of the OE to $10 \mathrm{ppm}$ of diazinon in APW. Details are described in the text.

microvalve 12, as shown in Figure 5 (characteristic results are shown in Figure 6(c)). Experiments 2, 4, 6-11, 13-17, and 19 were as follows: $10 \mathrm{~min}$ at a flow rate $0.5 \mathrm{~mL} / \mathrm{min}$ of APW from bottle 1 and then through column 6 in Figure 5 (characteristic results are shown in Figure 6(a)). One hundred microliters of the mixture of sex pheromones was injected using injector 4, as shown in Figure 5 (characteristic results are shown in Figure 6(b)). The flow of APW from bottle 1 through column 6 in Figure 5 continued for $10 \mathrm{~min}$ at a flow rate of $0.5 \mathrm{~mL} / \mathrm{min}$ (characteristic results are shown in Figure 6(a)). After $10 \mathrm{~min}$, the flow was switched to bottle 2 for 1 min and then directed through column 7 using injector 4, as shown in Figure 5. The flow from bottle 2 was then stopped and changed to flow from bottle 1 for 6 min with simultaneous redirection of the flow through column 6 using injector 4, as shown in Figure 5. In the stream of APW through column 6 using injector 4 with $100 \mu \mathrm{L}$ of the mixture of sex pheromones was injected using injector 4, as shown in Figure 5 (characteristic results are shown in Figure 6(d)).

\section{Results and Discussion}

Several studies have reported observations of behavioral changes in fishes exposed to OPs [31] [39]. The influence of OPs and carbamates on living creatures is more complex and involves more than the destruction of olfactory organ odor perception and Pavlovian reflexes connected to destruction of the olfactory organs, or shortor long-term disturbance of this organ. The idea of more complex involvement of intoxication by OPs and carbamates is supported by several publications [31] [35]-[39]. Because OPs, carbamates, and other substances such as cocaine can be transported in the ONs to the forebrain [34], the involvement of the telencephalon and 
hypothalamic-hypophyseal-pituitary-adrenal axis has been discussed [6] [40]. The changes in normal behavior may reflect telencephalic reactions [39] induced by OPs if the toxins are transported in the brain [34].

The belief that living creatures except hominids lack intelligence or even cognitive abilities and live only on the basis of Pavlovian reflexes is not correct. If we accept that fish lacks a well-developed memory and what are at present unknown cognitive abilities, it is impossible to explain certain phenomena; for example, how salmon and other fishes can find their hatching places in rivers and lakes and return there from their feeding places by traveling many thousands of kilometers in the open oceans.

Only disruption of cognitive abilities [39] or the presence in hatching places of chemical signals about lifethreatening danger can affect the normal reproductive behavior of fish. The present experiments showed that exposure to diazinon (a representative OP pesticide) can modify the nerve signals from the OB to the brain. The normal nervous activity in the OB when exposed to APW (Figure 6(a)) agrees with that reported in previous publications [1]-[5] and [20]-[22]. The nervous activity in the OB when exposed to alarm substances from fish skin extract (Figure 6(c)) agrees with that reported in previous publications [1]-[5]. The nervous activity in the OB when exposed to sex pheromones (Figure 6(b)) agrees with that reported in previous studies [20]-[22]. The nervous activity in the OB when exposed to sex pheromones after preexposure of the fish OE to $10 \mathrm{ppm}$ of diazinon for 1 min (Figure 6(d)) shows that, after preexposure to diazinon, injection of sex pheromones increased the nervous activity in the OB. These changes in nervous activity can be compared with those elicited by exposure of the OE to alarm substances in fish skin extract. Even the short-term preexposure to diazinon transformed the normal nervous signals from the $\mathrm{OB}$ to the brain to become signals about life-threatening danger. This can explain the behavioral change toward "not return to the hatching places in the rivers and lakes" in fish exposed to diazinon or other pesticides.

To understand the toxic effects of OPs and other pesticides on the populations of salmon and other migrating fishes, several other factors should also be considered as the transport of OPs to the brain [34]: telencephalic lesions [39] induced by OPs, influence of OPs as endocrine disruptors [40], and other factors [41].

\section{Conclusions}

The mechanism of behavioral changes in fish after exposure to diazinon was visualized as a change from nervous attraction signals to sex pheromones in the brain as attractants to alarm nervous signals of repulsion and danger.

The changes toward "not return to the hatching places in the rivers and lakes" maybe a result of abnormal nerve signals from the OE to the brain and/or brain damage [39] induced by the transport of OPs to the brain's "thesaurus" [34] and loss of memory about navigation and other important cognitive abilities [31].

The suppression of the production of a broad spectrum of bioactive substances by pesticides [41], including sex hormones in males and females [35], may play a significant role in the vanishing of fish populations.

The same toxic mechanisms as observed in fishes are applicable to all living creatures including humans [31] [35] [41].

\section{References}

[1] Brondz, I., Hamdani, E.H. and Døving, K.B. (2003) The Fish Olfactory System Used as an In-Line HPLC Neurophysiologic Detector NPD. $3^{\text {rd }}$ International Symposium on Separation in BioSciences SBS 2003: A 100 Years of Chromatography, Moscow, 13-18 May2003, Abstract O-27, 95.

[2] Brondz, I., Hamdani, E.H. and Døving, K. (2004) Neurophysiologic Detector (NPD)—A Selective and Sensitive Tool in High-Performance Liquid Chromatography, Chromatography B: Biomedical Sciences and Applications, 800, 41-47.

[3] Brondz, I., Hamdani, E.H. and Døving, K.B. (2004) International Scientific-Technical Conference Sensors Electronics and Microsystems Technology (SEMST-1), Odessa, 1-5 June 2004, Plenum Lecture, Abstract, 17.

[4] Brondz, I., Hamdani, E.H. and Døving, K.B. (2004) The European Chemoreception Research Organization ECRO 2004 Congress, Dijon, 12-15 September 2004, Abstract, 3.

[5] Brondz, I., Karaliova, L. and Ekeberg, D. (2006) Biosensors as Electronic Compounds for Detector in the High-Performance Liquid Chromatography (HPLC). Electronic Components and Systems, 3, 25-27. (In Russian)

[6] Ray, A., Chatterjee, S., Ghosh, S., Kabir, S.N., Pakrashi, A. and Deb, C. (1991) Suppressive Effect of Quinalphos on the Activity of Accessory Sex Glands and Plasma Concentrations of Gonadotropins and Testosterone in Rats. Archives of Environmental Contamination and Toxicology, 21, 383-387. http://dx.doi.org/10.1007/BF01060360 
[7] Browne, J.V. (2008) Chemosensory Development in the Fetus and Newborn. Newborn \& Infant Nursing Reviews, 8, 180-186. http://dx.doi.org/10.1053/j.nainr.2008.10.009

[8] Fishelson, L., Golani, D., Galil, B. and Goren, M. (2010) Comparison of the Nasal Olfactory Organs of Various Species of Lizardfishes (Teleostei: Aulopiformes: Synodontidae) with Additional Remarks on the Brain. International Journal of Zoology, 2010, Article ID 807913. http://dx.doi.org/10.1155/2010/807913

[9] Kleerekoper, H. (1969) Olfaction in Fishes. Indiana University Press, Bloomington.

[10] Hara, T.J. (1975) Olfaction in Fish. Progress in Neurobiology, 5, 271-335. http://dx.doi.org/10.1016/0301-0082(75)90014-3

[11] Hara, T.J. (1994) Olfaction and Gustation in Fish: An Overview. Acta Physiologica Scandinavica, 152, 207-217. http://dx.doi.org/10.1111/j.1748-1716.1994.tb09800.x

[12] Hara, T.J. (2005) Olfactory Responses to Amino Acids in Rainbow Trout: Revisited. In: Reutter, K. and Kapoor, B.G., Eds., Fish Chemosenses, Science Publishers, Enfield, 32-64.

[13] Atema, J. (1983) Chemical Senses, Chemical Signals, and Feeding Behavior in Fishes. In: Bardach, J.E., Magnuson, J.J., May, R.C. and Reinhart, J.M., Eds., Fish Behavior and Its Use in the Capture and Culture of Fishes (ICLARM Conference 5), International Center for Living Aquatic Resources Management, Manila, 57-101.

[14] Hara, T.J. and Zielinski, B.S. (1989) Structural and Functional Development of the Olfactory Organ in Teleosts. Transaction of the American Fishery Society, 118, 183-194. http://dx.doi.org/10.1577/1548-8659(1989)118<0183:SAFDOT>2.3.CO;2

[15] von Frish, K. (1938) Zur Psychologie des Fish-Schwarmes. Naturwissenschaften, 26, 601-606. http://dx.doi.org/10.1007/BF01590598

[16] von Frisch, K. (1942) Über einen Schreckstoff der Fischhaut und seine biologische Bedeutung. Zeitschrift für Vergleichende Physiologie, 29, 46-145.

[17] Gon, O. and Fishelson, L. (2009) Nasal Olfactory Organs and Olfactory Bulbs in Blennies. In: Patzner, R.A., Gonçalves, E.J., Hastings, P.H.A. and Kapoor, B.G., Eds., The Biology of Blennies, Science Publishers, Enfield, 188-213.

[18] Døving, K.B. (1966) Efferent Influence upon the Activity of Single Neurons in the Olfactory Bulb of the Burbot. Journal of Neurophysiology, 29, 675-683.

[19] Meredith, M. (1978) Patterned Response to Odor in Single Neurones of Goldfish Olfactory Bulb: Influence of Odor Quality and Other Stimulus Parameters. Journal of General Physiology, 71, 615-643. http://dx.doi.org/10.1085/jgp.71.6.615

[20] Hamdani, El.H. and Døving, K.B. (2003) Sensitivity and Selectivity of Neurons in the Medial Region of the Olfactory Bulb to Skin Extract from Conspecifics in Crucian Carp, Carassius carassius. Chemical Senses, 28, 181-189. http://dx.doi.org/10.1093/chemse/28.3.181

[21] Lastein, S. (2008) Olfactory Processing of Sex and Alarm Cues in the Crucian Carp Carassius carassius. PhD Thesis, University of Oslo, Oslo.

[22] Lastein, S., Hamdani El.H. and Døving K.B. (2008) Single Unit Responses to Skin Odorants from Conspecifics and Heterospecifics in the Olfactory Bulb of Crucian Carp Carassius carassius. The Journal of Experimental Biology, 211, 3529-3535. http://dx.doi.org/10.1242/jeb.018739

[23] Heczko E.J. and Seghers B.H. (1981) Effects of Alarm Substance on Schooling in the Common Shiner (Notropiscornutus, Cyprinidae). Environmental Biology of Fishes, 6, 25-29. http://dx.doi.org/10.1007/BF00001796

[24] Hüttel, R. (1941) Die chemische Untersuchung des Schreckstoffes aus Elritzenhaut. Naturwissenschaften, 29, $333-334$. http://dx.doi.org/10.1007/BF01481737

[25] Hüttel, R. and Sprengling, G. (1943) Über Ichthyopterin, einen blaufluorescierenden Stoff aus Fischhaut. Justus Liebigs Annalen der Chemie, 554, 69-82. http://dx.doi.org/10.1002/jlac.19435540107

[26] Purrmann, R. (1947) Pterine. Fiat-Bericht. Biochemie, 39, 84.

[27] Korte, F. and Tschesche, R. (1951) Über Pteridine. V. Mitteil: Die Konstitution des Ichthyopterins. Berichte der Deutschen Chemischen Gesellschaft, 84, 801-809.

[28] Ziegler-Giinder, I. (1956) Pterine: Pigmente und Wirkstoffe in Tierreich. Biological Reviews, 31, 313-348. http://dx.doi.org/10.1111/j.1469-185X.1956.tb01593.x

[29] Pfeiffer, W. and Lemke, I. (1973) Untersuchungen zur Isolierung und Identifizireung des Schreckstoffes aus der Haut der Elritze, Phoxinus phoxinus L. (Cyprinidae, Ostariophysi, Pisces). Journal of Comparative Physiology, 82, 407-410.

[30] Lebedeva, N.Ye., Malyukina, G.A. and Kasumyan, A.O. (1975) The Natural Repellent in the Skin of Cyprinids. Journal of Ichthyology, 15, 472-480.

[31] Scholz, N.L., Truelove, N.K., French, B.L., Berejikian, B.A., Quinn, T.P., Casillas, E. and Collier, T.K. (2000) Diazi- 
non Disrupts Antipredator and Homing Behaviors in Chinook Salmon (Oncorhynchus tshawytscha). Canadian Journal of Fisheries and Aquatic Sciences, 57, 1911-1918. http://dx.doi.org/10.1139/f00-147

[32] Petroianu, G.A. (2009). The Synthesis of Phosphor Ethers: Who Was Franz Anton Voegeli? Pharmazie, 64, $269-275$.

[33] Benmoyal-Segal, L., Vander, T., Shifman, S., Bryk, B., Ebstein, R., Marcus, E.-L., Stessman, J., Darvasi, A., Herishanu, Y., Friedman, A. and Soreq, H. (2005) Acetylcholinesterase/Paraoxonase Interactions Increase the Risk of Insecticide-Induced Parkinson's Disease. The FASEB Journal, 19, 452-454. http://www.fasebj.org/cgi/doi/10.1096/fj.04-2106fje

[34] Gross, G.W. and Kreutzberg, G.W. (1978) Rapid Axoplasmic Transport in the Olfactory Nerve of the Pike: I. Basic Transport Parameters for Proteins and Amino Acids. Brain Research, 139, 65-76. http://dx.doi.org/10.1016/0006-8993(78)90060-4

[35] Miranda-Contreras, L., Gómez-Pérez, R., Rojas, G., Cruz, I., Berrueta, L., Salmen, S., Colmenares, M., Barreto, S., Balza, A., Zavala, L., Morales, Y., Molina, Y., Valeri, L., Contreras, C.A., and Osuna, J.A. (2013) Occupational Exposure to Organophosphate and Carbamate Pesticides Affects Sperm Chromatin Integrity and Reproductive Hormone Levels among Venezuelan Farm Workers. Journal of Occupational Health, 55, 195-203.

[36] Racciatti, D., Vecchiet, J., Ceccomancini, A., Ricci, F. and Pizzigallo, E. (2001) Chronic Fatigue Syndrome Following a Toxic Exposure. The Science of the Total Environment, 270, 27-31. http://dx.doi.org/10.1016/S0048-9697(00)00777-4

[37] Behan, P.O. and Haniffah, B.A.G. (1994) Chronic Fatigue Syndrome: A Possible Delayed Hazard of Pesticide Exposure. Clinical Infectious Diseases, 18, S54.

[38] Abou-Donia, M.B. (2003) Organophosphorus Ester-Induced Chronic Neurotoxicity. Archives of Environmental Health: An International Journal, 58, 484-497.

[39] Davis, R.E., Reynolds, R.C. and Ricks, A. (1978) Suppression Behavior Increased by Telencephalic Lesions in the Teleost, Macropodus opercularis. Behavioral Biology, 24, 32-48. http://dx.doi.org/10.1016/S0091-6773(78)92866-3

[40] Poongothai, S., Ravikrishnan, R. and Murthy, P. (2007) Endocrine Disruption and Perspective Human Health Implications: A Review. The Internet Journal of Toxicology, 4. https://ispub.com/IJTO/4/2/3638

[41] Brondz, I. and Brondz, A. (2011) Suppression of Immunity by Some Pesticides, Xenobiotics, and Industrial Chemicals. In Vitro Model. Journal of Biophysical Chemistry, 2, 226-232. http://dx.doi.org/10.4236/jbpc.2011.23028 